\title{
Monitoring and evaluation of socio- economic impacts of Watershed Management Activities in Tar and Bar Watersheds of County Damavand, Tehran Province
}

\author{
Habibollah Mahdavivafa \\ Agricultural Research and Instruction and Natural Resources Center of Tehran Province, \\ Agricultural Research, Education and Extension Organization (AREEO) \\ Email: hmahdavi2000@gmail.com \\ Rahman Sharifi \\ Agricultural Research and Instruction and Natural Resources Center of Tehran Province, \\ Agricultural Research, Education and Extension Organization (AREEO) \\ Email: R_sharifi46@gmail.com
}

\begin{abstract}
Evaluation of socio-economic impacts of activities carried out in watersheds is of great importance.studies in the watershed of Tar and Bar Damavand in Tehran province indicate that in recent years, the volume of floods that occurred, in addition to the destruction and threat of Damavand, has also damaged agricultural lands and villages in the lower reaches of Damavand. In addition, wasting and loss of flood and water run off the extracted water, while the region faces problems in terms of surface water and underground water resources, including operations and activities Watershed in watersheds has effects and consequences that can be positive or negative depending on the activity. In order to understand the success rate and effectiveness of the plans implemented by the watershed management, it is essential that the implemented projects be evaluated. And according to the results, the positive effects were strengthened and the negative points were reduced. In this research project The economic and social impacts of the watershed activities in the watershed of Tar and Bar Damavand were studied using field studies and completion of the questionnaire and the effects of bogging operations, such as conservation and conservation projects, seedling, forage, seeding, etc. Rural users were evaluated in these areas. According to a survey by rural entrepreneurs, 86 percent of them consider the role of projects to be effective in reducing flood damage. Also, $65 \%$ of the rural population said they had a positive impact on livestock and livestock production. . In terms of rural use, 77 percent of them said they were effective in increasing their income. While 86 percent of rural utilities did not have any effect on these watershed projects.
\end{abstract}

Key Words: Watershed, Economic and Social Impacts, Basins Tar and Bar, Damavand.

Introduction:

In fact, the watershed is a unitary hydrological unit that is accepted as a physical, biological, political, social and economic unit for the design and management of natural resources (water, soil, vegetation). In fact, the objective concept of a watershed is as follows: Mountains whose lands are mostly forest, pasture and crops, and its inhabitants are mostly low income villagers and small farmers (Ahmadi, Hasan et al., 1996: 16). The watershed is a hydrological unit and today it has been adopted as a physical, biological, political, economic and social unit for the planning and management of all existing natural areas (Ziaee, 1991: 12). Water regeneration is the process of adjusting and implementing appropriate measures for the purpose of Managing resources in the watershed, in the interests of the community, without damaging the resources of these resources. Also watershed management, management and operation are coordinated, integrated and regulated natural resources, human and economic agriculture from a watershed. Provided that the main reservoir, which is its water and soil resources, is fully preserved and not negatively affected (Sheng, 1997: 23)

Considering the special geographical conditions of the country and water scarcity, especially in the agricultural sector, activities have been carried out for optimum use of water resources of the country. One of these important activities is the watershed management, which is carried out to protect the water and soil resources. In fact, activities carried out by humans in nature have effects and consequences that can be positive or negative depending on the type of activity. 
Rivers in Damavand province from the province of Tehran since 1991, its implementation was started by Damavand watershed management department. Its main objectives are: reduction of flood damage, vegetation improvement and increase of surface area the life of the rural exploiters, the creation of employment, and so on. During this period, biological and mechanical operations have been carried out at the level of these two basins. In this regard, the assessment of the economic and social impacts of the watershed management activities is considered as a priority area for water management projects, so that watershed management activities cannot be considered successful if they do not meet the social and economic needs of the countries. Thus, the evaluation of the economic and social effects of Watershed activities carried out in Tar and Bar river basins after more than 5 years of implementation of its watershed management has been evaluated.

Using field operations, completing the questionnaire and ... the amount of economic and social effects caused by the implementation of various activities on flood control, containment and precipitation, increasing livestock and agriculture, increasing water and changes in the process Immigration, employment and income. Therefore, by assessing these activities, the economic and social effects of the watershed operation and their impact on improving the resources (water and land), creating employment and staying in the rural area can be realized and if the projects fail, the cause is recognized and to resolve Obstacles and problems

The purpose of this research project is to: determine the type and extent of the socio-economic impacts of the watershed design of the watershed management activities carried out in the watershed of Tar and Bar. ( Mahdavivafa, H.2012:18).

The most important research questions:

Question 1: Implementation of Watershed Management Plan has increased the productivity of agricultural production.

Question 2: Implementation of Watershed Management Plan has increased employment.

Question 3: The implementation of the Watershed Plan has led to an increase in income.

Question 4: Implementation of Watershed Management Plan has reduced the migration to the outside of the

\section{Background research:}

Satterland.1982.In their study has concluded that watershed management plans in accordance with the logic of production and service offering to increase water harvesting and utilization of production watershed especially in the areas of water downstream and solve social problems associated with the restoration and development of watersheds cannot be considered successful design.

Kosar.A.1986.In his plan as "desertification with flood control," stated concerted effort that this project will provide a better ground for the growth of native plants. In years 1982-19871 equal 38 million cubic meters during the flood plain Grbaygan network has been restored and transformed the lives of its inhabitants and Revenue rose plantations. Production capacity of fast growing tree species in these networks to 10 tons per hectare per year. Navigation provides irrigation facilities on the one hand, and a dramatic increase in the price of agricultural commodities on the other hand, a group of rural urbanization has to return to Grbaygan.

Hudson.1991-In her project entitled "The causes of success and failure of soil and water conservation projects can be integrated as one of the studies considered in evaluating the results of this experiment indicates that soil conservation structures that simple and that they comply with the basic requirements and methods of operation and maintenance of water structures.

Baniasade.M.1995- In his study entitled "Effects of small water aquifer management plan of Bam on socioeconomic status of residents of small water" has. With the implementation of 500 hectares under cultivation has increased. Project in the region has caused many villages to work station area. Also in the area of migration are quite tangible projects has decreased.

Bakhtiyar-A.1998-Your plan entitled "Socio-economic Assessment flood spreading project Grbaygan" have provided. Calculations of the cost-benefit ratio $\mathrm{B} / \mathrm{C}=20$ is shown. Which indicate that water spreading, lowcost method of great efficiency. With increasing groundwater, the acreage of crops in the region increased from dry land to irrigated cropping pattern has changed. And rural life of one conventional dairy farms have changed the status of agriculture and employment has increased. Increased income level and its value has gained ground.

-Khobfekr.H.1999-In his study to evaluate the "economic, social and technological watershed management activities in Sistan and Baluchestan". Watershed's satisfaction with the activities carried out as one of the most important indicators is considered $00 \%$ of people who give their consent to the general plan of activities (watershed) have announced. Of these, $9 / 68 \%$ satisfaction very high, $20 \%$ high satisfaction, $7 \%$ are moderately satisfied and only $1 / 1 \%$ have expressed satisfaction with their loss $99 \%$ of people's participation in watershed management activities it deemed necessary because of the benefit of the people of these activities have enumerated 
-Sadeghi Seyyed Hemidreza et al.- 2005- In a research project entitled "Assessing the Performance of Watershed Management by Qualitative Method, Case Study: Part of the Catchment Basin". Results obtained during the qualitative assessment of watershed management practices in the Caspian region of the Watershed Using the questionnaire method, the reduction of the number of floods and the amount of water pollution caused by watershed management is shown. According to the villagers, the implementation of watershed management measures in the amount of crop production, the rate of immigration of the people of the region, and the change in the breadth of the area were $63 \%, 55 \%$ and 37\%, respectively (Geographic Reserach, winter 2005, No. 79).

Yazdani Mahmood, et.al.-2009- in a research project entitled "Assessing the Socio-Economic and Environmental Impacts of Watershed Management Plans, Case Study: Zanjanrood Planning Project") Study of Socio-Economic and Environmental Impact with Qualitative Method. The results of this study show that Zanjanrood's arrangement of flood control and cropping has been very successful and consequently the production and income of farmers has increased. $92 \%$ of respondents believed that the scheme had significant economic effects for farmers. (Journal of Geography - spring and summer 2009).

\section{Materials and methods:}

Damavand county with an area of 2026 square kilometers which is 10.7 percent of the province's area is located south of the central Alborz and east of Tehran province, north of Mazandaran province, south to Semnan province, east to Firoozkooh city and The west is limited to the cities of Shemiranat, Tehran and Pakdasht. The climate of this city is more profitable in areas affected by lower desert climates and in areas affected by wet northern and western cold masses. (Mahdavivafa, H.1993:8).

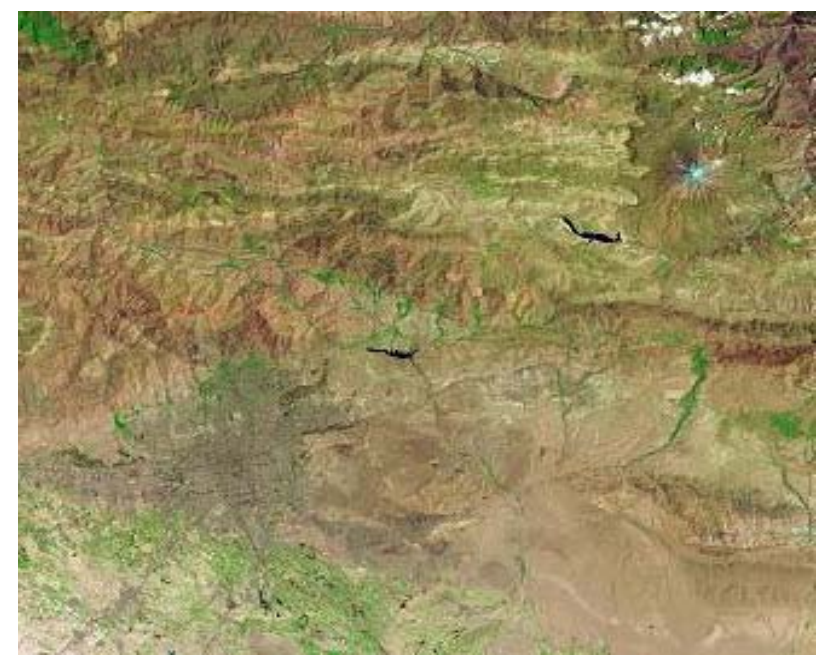

Image 1. Satellite images of Tehran province and Damavand County

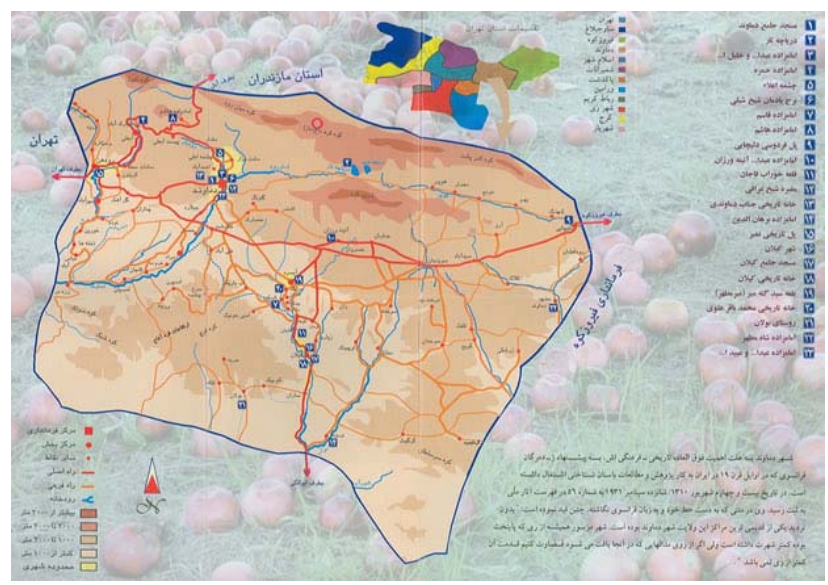

Image 2. Topographic map of Damavand city

Tar and bar basins with flood plain basins and mountainous and low-lying lands in high flood occurrences not only play a large part but also play a major role. Therefore, identification of the factors of the occurrence or intensification of the flood in the watershed basins of Tar and bar is considered as a community of exploiters. These basins have a surface area of 14,000 hectares with a population of more than 4000 people, while rural users $(47 \%)$ are interested in most gardening activities. Only in 1988, there were 8 deaths and up to $60 \%$ of the damage to rural areas. (Mahdavivafa ,H.2012:23). 
Factors affecting the destruction of natural resources in the region:

The diversity of the structure of the people in the region and the existence of various types of exploitation have had different effects on the destruction of the arenas, each of which has its own type of fluctuation and impacts, the most important of which are in general subdivided into a few groups: (Mahdavivafa, H.2012:30).
A) Land ownership and land playground
B)Immigration and Livelihoods in the City
C) urban migrants and villas (land use change)
D) lack of knowledge of how to use natural resources

Rivers in Damavand province have been started since 1991. Its executive operations were initiated by the Damavand watershed management department. Its main goals are: reducing flood damage, improving vegetation and increasing the living standards of rural landowners, Creating employment and.... During this period, biological and mechanical operations have been carried out on the surface of these two basins. Of course, important issues such as proper location, drought, specific geographic conditions and implementation management can be effective in achieving the desired goals.

Considering that in the years 1990 to 1991 the Damavand Watershed comprehensive plan was prepared by Jihad engineering Services Company and the watershed management employer of Tehran province. Then, based on this comprehensive plan, prioritizing the preparation of detailed executive plans has been carried out. Detailed executive studies of watersheds Tar and Bar Damavand during 1995-1997 in 9 volumes was carried out by Abkhizan Consulting Engineers to the Employer of Watershed Management in the province of Tehran. From 1996 to 2001, the implementation of mechanical and biological operations in the form of executive plans was completed and completed (Mahdavivafa, H.2012:12).

Considering the major activities of watershed management in these basins, there are 419 flood straits, 309 chains of china, 94 chapters, 29 girths with a length of 1465 square meters and the construction of a bank at a level of 28 hectares in 6 Section. By carrying out these activities, according to the consultant's report, the operation of remediation and restoration of rangelands in addition to establishing appropriate vegetation cover for the soil of the area prevents the occurrence of floods that also regularly threatened Damavand city.

The most important goals of implementing the watershed management plans in the watershed waters of Damavand are: (Mahdavivafa, H-2012:18).

- increase the amount of water caused by the implementation of the methods

- Prevention of Flood Damage

- Increase fodder

- seedlings

- erosion and sediment control

In this study, the available existing study reports, including the technical evaluation plan, were carried out by the engineering consultants of Omran-e-water Pardisan, which was carried out in 2006 in the catchment area of Tar and Dam basins in Damavand city. In this way, the assessment of the watershed operations and operations includes a variety of biological operations (protection and exclusion, planting, planting, forage and seeding), and mechanical operations (landfill, bunkering, river basin stabilization, protective wall). The following are: (Engineers and Supervisor of Civil Engineering, Pardisan Water Company, 2006:14).

\section{Discussion:}

The scope of this research includes rural areas, Urea, Ahmadabad, Dashtban, Jashmeh Ala, Dashtak, Dashtmasar, Masahar (Table 8)

Table 8- Changes in population of villages in Tar and Bar watershed from 1975 to 2006

\begin{tabular}{cccccc}
\hline Row & Village & $\mathbf{1 9 7 6}$ & $\mathbf{1 9 8 6}$ & $\mathbf{1 9 9 6}$ & $\mathbf{2 0 0 6}$ \\
\hline $\mathbf{1}$ & Urea & 1265 & 1171 & 926 & 863 \\
$\mathbf{2}$ & Ahmadabad, & 721 & 682 & 1245 & 1368 \\
$\mathbf{3}$ & Dashtban & 516 & 465 & 416 & 385 \\
$\mathbf{4}$ & Jashmeh Ala & 562 & 528 & 498 & 421 \\
$\mathbf{5}$ & Dashtak & 439 & 432 & 386 & 341 \\
$\mathbf{6}$ & Dashtmasar & 386 & 326 & 412 & 376 \\
$\mathbf{7}$ & Masaha & 564 & 730 & 1460 & 161 \\
$\mathbf{8}$ & Manzariyeh & 86 & 162 & 284 & 329 \\
$\mathbf{-}$ & Total & $\mathbf{4 5 3 9}$ & $\mathbf{4 4 9 6}$ & $\mathbf{5 6 2 7}$ & $\mathbf{4 2 4 4}$ \\
\hline
\end{tabular}

Source: Iran Statistics Center. Population Census and Housing. 1976, 1986, 1996 and 2006 
In this research, in addition to the library and documentary method, field research method has been used to obtain the necessary information from the research supply according to the questions asked by the rural villagers. After completing the questionnaires, descriptive analytical method was used to analyze the data of the questionnaires. Considering that the watershed management plans carried out at the level of these basins with the objectives of controlling and fighting erosion, wastewater and soil, optimizing the use of resources and soil, increasing the production of watersheds as plant and animal production, increasing the income of residents of watersheds and reducing the damage caused from soil erosion, floods and floods and so on. Therefore, the analysis based on the survey of rural farmers in the form of a questionnaire in the direction of changes in the trend of increasing livestock, livestock, immigration, employment, income, etc., has been carried out using a large percentage of them.

Analysis based on the data obtained The changes in the process of migration, employment, income, using percentages on them, and for each of the watershed management activities, the socioeconomic effects and comparison of the results of the opinion polls of the people in the form of a questionnaire for the regions Rural and sub-basin operators, and percentage of socio-economic changes.

Considering the statistical population, the total households of eight villages inhabited by Tar and Bar Damavand watershed basins in 2006 equal to 1206 households. The sample size was 130. The number of completed questionnaires from the head of households in rural areas has been filled up with 130 questionnaires according to the number of absolute households in each village. Based on their data, the socioeconomic analysis of the watershed activities in the Tar and Bar watersheds has been studied. To investigate the effects Economic and social activities of watershed management in Tar and Dam watersheds in Damavand according to a questionnaire prepared by rural users. Based on the research method, the interviewed people included five groups: farmer, farmer, farmer, farmer and farmer. The frequency of the employment of the rural municipality is shown in Table 1.

Table 1 - Frequency of Occupation in rural dormitories

\begin{tabular}{|c|c|c|}
\hline Occupation & Number & Frequency to percentage \\
\hline Farmer & 19 & 14.6 \\
\hline Animal husbandry & 55 & 42.3 \\
\hline Farmer- Animal husbandry & 35 & 29.9 \\
\hline colonizer & 21 & 16.1 \\
\hline TOTAL & $\mathbf{1 3 0}$ & $\mathbf{1 0 0}$ \\
\hline
\end{tabular}

Source: (Mahdavivafa, H.2012:41)

\section{Conclusion:}

Watershed activities in the watershed of Tar and bar rivers in Damavand have been operational since 1380, and its main objectives are the following: reduction of flood damage, improvement of vegetation and raising the living standards of rural exploit ants, creating employment and ... Considering the socioeconomic effects of water catchment plans in Tar and Bar basins, the suggestions presented in this study are based on the information obtained from the questionnaire and the summary of the results and the answers to the questions presented below:( Mahdavivafa, H-2012:46).

\section{Question 1: Implementation of Watershed Management Plan has increased the productivity of agricultural} production

Facial examinations, such as the results of biological and mechanical activities and information from rural users, have suggested that the operation of watershed management has led to an increase in livestock production, or $65 \%$ of respondents have stated that in this regard, there were 77 percent of the exploiters in the field of increasing forage production in rangelands, which increased the yield of crops and rangelands (Table 2 and 3). 
Table 2. How much did it increase in crop production compared to the implementation of the project?

\begin{tabular}{|c|c|c|}
\hline Row & User comments & People to percent \\
\hline 1 & Very high (more than 3 times) & 10 \\
\hline 2 & Relatively high (equivalent to 3 times) & 56 \\
\hline 3 & High (equivalent to 2 times) & 34 \\
\hline 4 & Average (equivalent to 1) & - \\
\hline \multicolumn{2}{|c|}{ TOTAL } & $\mathbf{1 0 0}$ \\
\hline
\end{tabular}

Table 3. How much was the amount of forage in front of the project?

\begin{tabular}{|c|c|c|}
\hline Row & User comments & People to percent \\
\hline 1 & Very high (more than 3 times) & 5 \\
\hline 2 & Relatively high (equivalent to 3 times) & 24 \\
\hline 3 & High (equivalent to 2 times) & 71 \\
\hline 4 & Average (equivalent to 1) & 0 \\
\hline 5 & Low (less than 1 time) & 0 \\
\hline \multicolumn{2}{|c|}{ TOTAL } & $\mathbf{1 0 0}$ \\
\hline
\end{tabular}

Question 2: Implementation of Watershed Management Plan has increased employment.

Approximately $14 \%$ of the respondents stated that the watershed operation was employed, while $86 \%$ stated that they did not affect employment (Table 4)

Table 4: How much has it affected if employment is increased?

\begin{tabular}{|c|c|c|}
\hline Row & User comments & People to percent \\
\hline 1 & Very much & 0 \\
\hline 2 & Fairly high & 0 \\
\hline 3 & very & 0 \\
\hline 4 & Average & 89 \\
\hline 5 & Low & 11 \\
\hline \multicolumn{2}{|c|}{ TOTAL } & $\mathbf{1 0 0}$ \\
\hline
\end{tabular}

Question 3: Has the implementation of the Watershed Plan has led to an increase in income.

In the context of increasing per capita income of villagers, 68 percent of the respondents said that 32 percent said they had no effect. Thus, it has had a significant effect on income growth (Table 5).

Table 5: Has household income risen by implementing watershed management plans

\begin{tabular}{|c|c|c|}
\hline Row & User comments & People to percent \\
\hline 1 & NO & 68 \\
\hline 2 & YES & 32 \\
\hline \multicolumn{2}{|c|}{ TOTAL } & $\mathbf{1 0 0}$ \\
\hline
\end{tabular}

Question 4: Implementation of Watershed Management Plan has reduced the migration to the outside of the region.

According to surveys, 17 percent of the respondents stated that the implementation of water management plans in this area has reduced immigration, while 88 percent said they did not have any effect (Table 6). Also, in the case of reverse migration, it was also stated that $16 \%$ had an impact and $84 \%$ had no effect (Table 7 ). Thus, these watershed initiatives did not reduce migration in the Taro basin. 
Table 6 - Has the implementation of the Watershed Plan has reduced the migration of villagers to other areas?

\begin{tabular}{|c|c|c|}
\hline Row & User comments & People to percent \\
\hline 1 & NO & 12 \\
\hline 2 & YES & 88 \\
\hline \multicolumn{2}{|c|}{ TOTAL } & $\mathbf{1 0 0}$ \\
\hline
\end{tabular}

Table 7: Has there been a reverse migration trend in the region with the implementation of the Watershed Plan?

\begin{tabular}{|c|c|c|}
\hline Row & User comments & People to percent \\
\hline 1 & NO & 16 \\
\hline 2 & YES & 84 \\
\hline \multicolumn{2}{r|}{ TOTAL } & $\mathbf{1 0 0}$ \\
\hline
\end{tabular}

Regarding the implementation of watershed plans in this area, with the views of rural farmers, $65 \%$ of the respondents stated that they increased agricultural production and $77 \%$ stated that they increased their forage production and thus increased livestock production in the villages. In the meantime, about 86 percent of rural villagers in the area have stated that they have had an impact on the implementation of water plans, which has reduced flood damage. In most cases, running water projects do not generate direct income.

Therefore, the implementation of these plans will not be an incentive to consolidate the village population or reverse migration to the village, although in some cases the population stabilization and survival in the village have been relatively relative. Regarding job creation, rural entrepreneurs were not job-seekers, and about 86 percent of the respondents stated that they had no impact on employment. In the context of increasing per capita income, 68 percent of the respondents said that 32 percent had stated that It has had no effect on the increase in revenue.

Due to the fact that the distance and the limited capacity of farmland, Rangeland because of mountainous region of the area and the lack of full facilities for life including: school, suitable way and health facilities, $17 \%$ of the respondents stated that the implementation of the watershed plans in This region has reduced immigration, while $88 \%$ said it did not have any effect. Also, in the case of inverse immigration, it was stated that $16 \%$ had an impact and $84 \%$ did not affect the implementation of watershed initiatives to reduce immigration in basins The Taro Bar Damavand watershed has not had much impact.

\section{Suggestions:mm}

Due to the fact that in the Tar and Bar basins of Damavand, the majority of rural vectors are dairy farmers, therefore, their activity is directly related to the status of the watershed in terms of vegetation. The implementation of bio-logical projects and their implementation will have a direct impact on the increase or decrease of rural entrepreneurs' incomes, so bio-logic projects should be pursued with greater sensitivity and care and the participation of people in the implementation of projects is a must. Long-term hangings are more than Four years will often cause problems for areas adjacent to the enclosed area and will exacerbate the pressure on these ranges, and in fact the restoration of the enclosed area will lead to further degradation of the adjacent area.

-Therefore, given the ecological potential of the region, it provides the possibility of short-term shelters and for a maximum of two years the possibility of regeneration and restoration of rangelands, and providing shelter for more than two years due to destructive effects on rangelands adjoining them.

-Basins of Tar and Bar county of Damavand due to special geological conditions and geomorphology governing it and sensitive geological formations and slopes of the slopes are often unstable and, in this case, changing land use, especially villages in this area, management of the arena It requires special natural resources and with proper planning, while using natural areas, maintains the balance of the ecosystem of the existing watershed, otherwise it will cause a great deal of damage due to floods of flood area and sediment production.

-Medium term and long-term planning for comprehensive management of Damavand Tar and Waters catchment basins with the participation of villagers and prioritizing biological projects, the prevention of land use change and the enjoyment by villagers of minimum amenities can provide land ecosystem sustainability. Creation and success of water management plans. 


\section{References:}

[1] Ahmadi, Hasan; Peymanfard, B; Kowsar. S., A.; Mahdavi, M. - 1996. Agricultural Culture and Natural Resources, Delta, Range and Watershed Management, First Edition, Tehran University Press. (In Persian).

[2] Bakhtiyar, Assadullah, -1998. Socioeconomic evaluation of Flood Flood Transmission Project Fasa, Natural Resources and Animal Sciences Research Center, Fars. (In Persian).

[3] Baniasadi, Mohsen-1995. Study and study of the effect of Bam aquatic fault design on the economic and social status of the residents of the region, Natural Resources and Animal Sciences Resear8. Iran Statistics Center-1976. The general number of people and housing (in Persian).

[4] Civil Engineers of Pardisan Water, 2006. Technical appraisal of waterproofing projects in Tar and Damavand basins. (In Persian).

[5] Hudson, R, E. 1991, Resource for success or failure of soil conservation, project, FAO.

[6] Iran Statistics Center-1976. The general number of people and housing. (In Persian).

[7] Iran Statistics Center-1986. The general number of people and housing. (In Persian).

[8] Iran Statistics Center. 1996. The General Population and housing. (In Persian).

[9] Iran Statistics Center-2006. The general number of people and housing. (In Persian).

[10] Khobfekr.H.-1999- Economic, social and technical evaluation of watershed management activities in Sistan-Baluchestan province. Natural Resources and Bestial Affairs Researches Center of Sistan and Baluchestan. (In Persian).

[11] Kosar.A. - 1986. Desertification with flood spreading. (In Persian).

[12] Mahdavivafa. Habibollah-2012. Research project Socio-economic impacts of Watershed activities carried out in Damavand Tar and BaR basins from the perspective of rural exploiters". Agricultural and Natural Resources Research Center of Tehran Province. (In Persian).

[13] Sadeghi Seyed Hemidreza, Frootan Elham, Sharifi Landing -2005 - Evaluation of the performance of watershed management by qualitative method (Case study: part of the watershed of Ken). Quarterly Journal of Geographical Research, winter 2005, No. 79.14-(in Persian).

[14] Satterland, R, D. 1982, Widland watershed Managment, Ronald Press, New York.

[15] Sheng, Ye. -1997. Guidance on watershed management,.Translate persian by Ali Najafinejad, Faculty of Agricultural Sciences and Natural Resources of Gorgan.

[16] Ziaei, Hujjatullah 1991. Principles of Watershed Engineering, Astan Quds Razavi Publishing. (In Persian).

[17] Yazdani Mahmood, Jalalian Hamid, Parzi Zanganeh Abdolhossein -2009- Evaluation of socio-economic and environmental impacts of watershed management (Case study: Zanjanrood's plan), Geography Quarterly - Spring and Summer 2009. (In Persian). 